\title{
Development of Performance Prediction Models for Gravel Roads Using Markov Chains
}

\author{
Waleed Aleadelat ${ }^{1}{ }^{*}$, Shaun Wulff ${ }^{2}$, Khaled Ksaibati ${ }^{1}$ \\ ${ }^{1}$ Department of Civil and Architectural Engineering, University of Wyoming, Laramie, USA \\ ${ }^{2}$ Department of Statistics, University of Wyoming, Laramie, USA \\ Email address: \\ waleadel@uwyo.edu (W. Aleadelat),wulff@uwyo.edu (S. Wulff), Khaled@uwyo.edu (K. Ksaibati) \\ ${ }^{*}$ Corresponding author
}

\section{To cite this article:}

Waleed Aleadelat, Shaun Wulff, Khaled Ksaibati. Development of Performance Prediction Models for Gravel Roads Using Markov Chains. American Journal of Civil Engineering. Vol. 7, No. 3, 2019, pp. 73-81. doi: 10.11648/j.ajce.20190703.12

Received: April 22, 2019; Accepted: May 28, 2019; Published: July 22, 2019

\begin{abstract}
The Wyoming technology Transfer Center (WYT2/ LTAP) is currently in the process of developing a Gravel Roads Management System (GRMS) in Wyoming. One of the major components of this new GRMS is developing a comprehensive optimization methodology for Maintenance and Rehabilitant (M\&R) activities. To support the new optimization methodology, this research study established multiple performance models to predict the deterioration patterns of gravel roads in Wyoming. Condition data, in addition to the average deterioration rates, for approximately $1931 \mathrm{~km}$ (1200 miles) of gravel road segments were used to develop these models. A probabilistic modeling approach using Markov Chains (MC) was adopted in this study to establish these prediction models. The developed prediction equations obtained from fitting these models include all the possible deterioration modes of gravel roads such as potholes, washboards, loose aggregate, and rutting. Generally, it was found that the average service life of a gravel road is around 12 months without any maintenance intervention. In addition, potholes, rutting, and washboards are the main failure modes for these types of roads.
\end{abstract}

Keywords: Gravel Roads, Markov Chains, Performance Models

\section{Introduction}

The Wyoming Technology Transfer Center (WYT2/ LTAP) is currently in the process of developing a Gravel Roads Management System (GRMS). Such a GRMS is intended to provide feasible practices to help local agencies in dealing with the different challenges associated with maintaining gravel roads in the state. One of the main goals of this project is to develop an optimization tool that can help decision makers at the local level in managing limited budgets and in selecting gravel roads for maintenance and rehabilitation (M\&R) projects. The tool, which has been developed, implements an optimization model that works on maximizing the overall gravel roads network conditions considering traffic volumes and subject to the limited budgets. It is well known that the estimation of a gravel road potential service life is one of the integral parts of any maintenance assignment process [1-3]. Therefore, this paper aims at developing performance prediction models to the gravel roads in Wyoming. Such prediction equations provide a mathematical representation of how a gravel road in Wyoming may deteriorate over time.

In addition to the general lack of the available GRMS that are tailored to suit the needs of small local agencies, research efforts are more designated towards solving specific issues related to managing gravel roads within the premise of the developing agency [1, 4-10]. This explains the importance of establishing specific rules, guidelines, and models that are designated for Wyoming gravel roads rather than following the generic practices available in the literature.

Currently, WYT2/ LTAP utilizes inexpensive, less labor intensive windshield surveys to evaluate gravel road conditions. Most of these surveys are modifications to the Pavement Surface Evaluation and Rating (PASER) guide developed by the Wisconsin Transportation Information Center [11, 12]. Two of these modifications are the Ride Quality Rating Guide (RQRG) and the Gravel Roads Rating Standards (GRRS). The RQRG reflects the perceptions of road users with regards to the driving quality of the gravel 
road. The GRRS describes the condition of a gravel road by providing specific rating for each distress or deterioration mode, such as, potholes, rutting, washboards, and loose aggregate [12]. With gravel roads, different maintenance practices are assigned according to the severity and extent of every distress available within the road surface. For example, poor potholes conditions require heavy blading to maintain the road while poor loose aggregate requires chemical treatment. Hence, it is necessary to have a specific performance model that describes the behavior of any gavel road in the means of every distress. These models will be implemented in the optimization process to elect the best maintenance practices and to assign cost effective budgets. Predicted performance models will be developed using Markov Chains (MC) [13]. The implementation of this probabilistic modeling approach has been widely used in the management of paved roads as it is flexible and requires minimal historical data to develop performance models. This probabilistic approach requires at least 2 successive periods of road conditions data. In cases where historical data is not available, expert opinions can be used to develop the performance models [14-19].

Gravel roads are dynamic as their conditions change dramatically based on different traffic and weather conditions. Also, these kinds of roads normally serve very low traffic volumes, which explains some of the indifference when it comes to the management of gravel roads [2, 9, 12]. The World Bank developed software to predict the performance of these roads such as the Roads Economic Decisions Model, the Deterioration of Unpaved Roads (DETOUR) Model, Highway Development and Management model (HDM-4), and the Roads Economic Decision Model (RED) [3, 4, 7, 21]. These models are used to run economic evaluations related to road investment projects. However, these models require a lengthy inputs list that may supersede the capabilities of small local agencies. These inputs are related to surface roughness, terrain type, traffic conditions, crashes, fatalities, injuries, speed, and geometric features [4, 7]. Also, they are more appropriate for project level analysis rather than network level analysis. Moreover, the extensive outputs may overthrow the small operating agencies $[3,4,21]$. Nonetheless, a few studies report the implementation of MC to predict the performance of gravel roads $[1,3]$. However, the models or methodologies are still exclusive and cannot be generalized for use by developing agencies. For example, the models by Chamorro and Tighe depend on specific indices like the Unpaved Roads Condition Index (UPCI) which is developed solely to evaluate gravel roads in Chile [3]. In addition, it is apparent that local agencies in Chile use other deep stabilization methods for gravel roads different from the ones followed in the US, which explains the long service life of these roads (e.g., 4 years). Deep stabilization process, such as the Full Depth Reclamation (FDR) method, includes deeply mixing chemical stabilizers into the roadbed. In such methods, roadbed materials are deeply crushed, blended, and mixed with chemical stabilizers to achieve a more stable road surface that can serve traffic for multiple years [22].

This research study utilizes gravel roads condition data collected from Laramie County, located in southeastern part of Wyoming, to develop the performance prediction models. The following sections describe the data collection efforts and the application of MC to develop these predictions. The prediction models developed here will be used solely to establish a large scale optimization model applicable to the gravel roads network for every county in Wyoming. The reader is referred to Hassan et al. for more extensive details for the methodology behind the MC and its implementation in road management [13]. This methodology involves characterization of the states, setting the initial state vector and start condition, investigating the number of cycles, and obtaining the transition probability matrix (TPM). This paper describes each of these steps as well as the data collection process and the development of one performance prediction model using the MC approach. Additional performance models will be summarized at the end of this paper.

\section{A Case Study: Laramie County}

Laramie County is located in the southeastern part of the state of Wyoming. In this county, there are about 700 gravel roads with a total approximate length of $1931 \mathrm{~km}(1200$ miles). This county was selected to perform a pilot study prior to the statewide implementation of the new GRMS. One team spent 2 months of field work in Laramie County and evaluated the entire gavel road network during the summer of 2017. This intensive data collection effort resulted in a comprehensive dataset that is used to build the performance prediction models and ultimately the GRMS. The following subsections describes the data collection process and the current conditions of the network.

\subsection{Surface Evaluation}

The WYT2/ LTAP utilizes inexpensive, less laborintensive windshield surveys such as GRRS and RQRG to evaluate gravel road conditions. The RQRG reflects the perceptions of roads users with regards to the driving quality of gravel roads. Table 1 shows a brief description of the RQRG system. This system rates gravel roads on a scale from 1 (failed) to 10 (excellent) and it is more affected by surface deformation modes like potholes, washboards, and rutting.

Table 1. Ride Quality Rating Guide' ratings, speeds and brief verbal description.

\begin{tabular}{lll}
\hline Rating & Speed in $\mathbf{K m} / \mathbf{h} \mathbf{~ ( m i / h )}$ & Description \\
\hline 10 Excellent & $96+(60+)$ & \\
9 Very Good & $80(50)-96(60)$ & \\
8 Good & $72(45)-80(50)$ & Dust under dry conditions; Moderate loose aggregate; Slight washboarding \\
7 Good & $64(40)-72(45)$ & \\
\hline
\end{tabular}




\begin{tabular}{|c|c|c|}
\hline Rating & Speed in $\mathrm{Km} / \mathrm{h}(\mathrm{mi} / \mathrm{h})$ & Description \\
\hline 6 Fair & $51(32)-72(40)$ & \multirow{2}{*}{$\begin{array}{l}\text { Moderate washboarding ( } 25.4 \mathrm{~mm}(1 ")-50.8 \mathrm{~mm}(2 ") \text { deep) over } 10 \%-25 \% \text { of area; Moderate dust, } \\
\text { partial obstruction of vision; None or slight rutting (less than } 25.4 \mathrm{~mm}(1 ") \text { deep); An occasional small } \\
\text { pothole (less than } 50.8 \mathrm{~mm}(2 ") \text { deep); Some loose aggregate ( } 50.8 \mathrm{~mm}(2 ") \text { deep) }\end{array}$} \\
\hline 5 Fair & $40(25)-51(32)$ & \\
\hline 4 Poor & $32(20)-40(25)$ & \multirow{2}{*}{$\begin{array}{l}\text { Moderate to severe washboarding (over } 76.2 \mathrm{~mm}(3 ") \text { deep) over } 25 \% \text { of area; Moderate rutting } \\
(25.4 \mathrm{~mm}(1 ")-76.2 \mathrm{~mm}(3 ")) \text { over } 10 \%-25 \% \text { of area; Moderate potholes }(50.8 \mathrm{~mm}(2 ")-101.6 \mathrm{~mm} \\
(4 ") \text { deep) over } 10 \%-25 \% \text { of area; Severe loose aggregate }(101.6 \mathrm{~mm}(4 "))\end{array}$} \\
\hline 3 Poor & $24(15)-32(20)$ & \\
\hline $\begin{array}{l}2 \text { Very Poor } \\
1 \text { Failed }\end{array}$ & $\begin{array}{l}13(8)-24(15) \\
0-13(8)\end{array}$ & $\begin{array}{l}\text { Severe rutting (over } 76.2 \mathrm{~mm}(3 ") \text { deep) over } 25 \% \text { of area; Severe potholes (over } 101.6 \mathrm{~mm} \text { (4") deep) } \\
\text { over } 25 \% \text { of area; Many areas (over } 25 \% \text { ) with little or no aggregate }\end{array}$ \\
\hline
\end{tabular}

* Passenger car speeds based on surface condition allowing for rider comfort and minimal vehicle wear and tear, assuming no safety or geometric constraints force slower travel. (Does not spill your coffee!)

** Individual roadways may not have all of the types of distress listed for any particular rating. They may have only one or two types.

The GRRS system evaluates a gravel road from a decisionmaker viewpoint, which explains the inclusion of drainage conditions along the other gravel roads deformation modes (i.e. washboards) [12]. According to this system, a higher rating means a better condition. The GRRS system includes the following distresses or deterioration modes:

1. Potholes; Rating scale [1-9],

2. Washboards; Rating scale [1-9],

3. Rutting; Rating scale [1-9],

4. Loose Aggregate; Rating scale [1-9],

5. Cross Section (Crown); Rating scale [1-3],

6. Roadside Drainage; Rating scale [1-3],

7. Dust; Rating scale [1-4].

The GRRS and the RQRG systems are used simultaneously to define the best treatment practice applicable to a gravel road. The GRRS ratings are necessary to define the best treatment practice for every individual distress. Then the GRRS rating and the RQRG are used together to define the final treatment option for each road according to a decision-matrix designed solely for local agencies in Wyoming.

The rating team used 2 vehicles, a 2010 Ford (F-150) pickup truck and a 2010 Chevy suburban, to perform the surface evaluation process. These vehicles were selected as many Wyoming locals in these areas tend to drive this kind of vehicles due to the severe weather/road conditions in the state. During the rating process, the rating team performed a road segmentation process based on many factors such as: usage levels, changes in surface type, intersections, surface conditions, and type of surroundings (i.e. crops or houses). The main purpose of the segmentation was to obtain uniform, consistent, homogeneous, and more representative ratings. Microsoft Streets, Trips software, and Global Positioning System (GPS) coordinates were used to locate these roads and its accompanied sub-segments at a site. During the data collection process, both ratings the GRRS and RQRG were collected for every gravel road.

\subsection{Laramie Gravel Road Conditions}

Figure 1 illustrates the evaluation results of gravel roads in Laramie County. From the figure, it can be noted that $75 \%$ of the roads are found to be in fair to good overall condition, and only $1 \%$ of the roads are in failure condition. It is apparent from this figure, that the loose aggregate conditions represent the best condition compared to the other distresses with $96 \%$ of the roads falling in the fair to the good categories. On one hand, the evaluation results show that the majority of Laramie County gravel roads $(57 \%)$ generate very high dust. On the other hand, only $27 \%$ of these roads have no or very low dust emissions. Generally, gravel roads in Laramie County have good cross-section or crown conditions, as $81 \%$ of these roads fall in the good category. Similarly, $82 \%$ of these roads have good drainage conditions.

\section{Performance Modeling}

Markov chain theory is used to develop the performance prediction models for each distress or deterioration mode related to gravel roads. The implementation of this probabilistic approach within any stochastic process requires that such a process be discrete in time and has determinate states. Additionally, the future condition of this process should be solely dependent on the present condition of the process [13]. These prerequisites apply to gravel road networks. For example, it is prevalent to analyze road networks within definite time points and to establish stationary states that describe road conditions at various time periods. Furthermore, the future condition of any gravel road is solely dependent on it is current state, not it is previous conditions.

The modeling process using the Markov chain theory involves 3 main steps, which are, in order, the development of state vectors, transition probability matrices (TPM), and lastly, the development of the prediction models. These steps will be described in more detail in the following subsections. However, before starting the Markov process, the number of states for each distress and the length of stages or duty cycles must be defined. Due to the dynamic nature of gravel roads and their short service life, monthly duty cycles are selected. Table 2 shows the number of states (categories) assigned for each distress. Any gravel road, during its service life, will transition through these different states without any maintenance intervention. According to the GRRS standards, it is advised to give integer ratings to place a gravel road within any condition category for simplicity purposes. In the field, it is not rational to discriminate between any two gravel roads by tenths of a point. 
Table 2. Number of States Assigned for Each Distress.

\begin{tabular}{llll}
\hline Distress & Category & Given Rating (R) & Possible Field Ratings \\
\hline & Very Good (VG) & $8<\mathrm{R}$ & 9 \\
& Good (G) & $6<\mathrm{R} \leq 8$ & 7,8 \\
Potholes; Rutting; Washboards; Loose Aggregate & Fair (FA) & $4<\mathrm{R} \leq 6$ & 5,6 \\
& P (Poor) & $3 \leq \mathrm{R} \leq 4$ & 3,4 \\
& Very poor (VP) & $2 \leq \mathrm{R}<3$ & 1 \\
& Failed (F) & $\mathrm{R}<2$ & 4 \\
& None (N) & $3<\mathrm{R}$ & 3 \\
Dust & Low (L) & $2<\mathrm{R} \leq 3$ & 2 \\
& Medium (M) & $1<\mathrm{R} \leq 2$ & 1 \\
& High (H) & $\mathrm{R} \leq 1$ & 3 \\
Cross Section (Crown); Drainage & Good (G) & $2<\mathrm{R} \leq 3$ & 2 \\
& Fair (FA) & $1<\mathrm{R} \leq 2$ & 1 \\
\hline
\end{tabular}

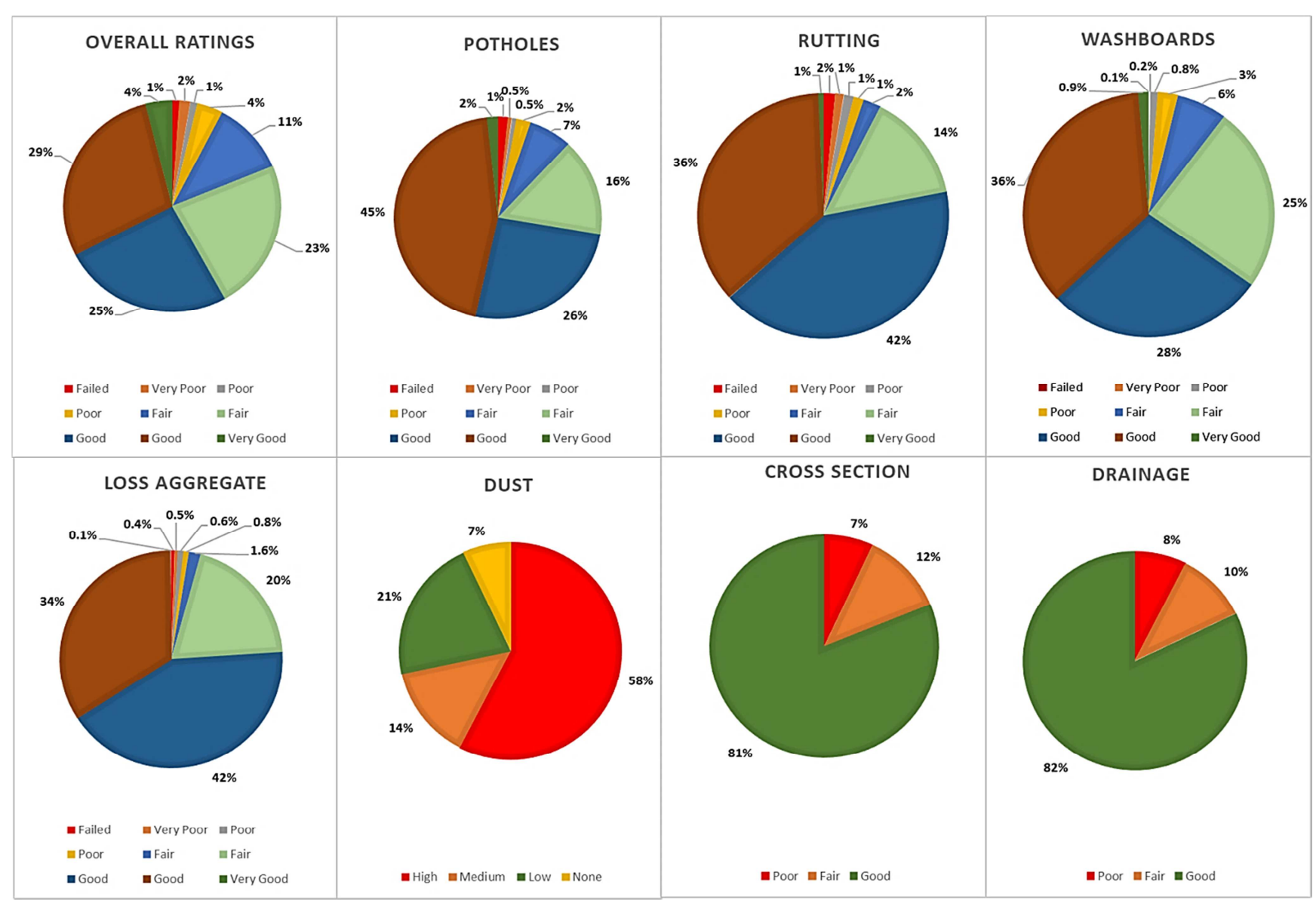

Figure 1. Laramie County Gravel Road Conditions as of Summer 2017.

\subsection{State Vectors}

There are two types of state vectors according to the MC modeling approach. These types are the initial vector and the start vector, which both define the probability of a gravel road to be in one of the condition states at age $(0)$ of the duty cycle. The difference between these types is that the initial vector assumes that all gravel roads have conditions similar to the conditions right after construction (i.e., perfect shape).
The start vector is based on the current gravel road conditions and the proportion of the network length that falls in each state category. The initial vector concept is followed in this study. Based on the collected data in the summer of 2017, some of the estimated start vectors and an initial vector for Laramie County gravel roads are shown in Table 3. It should be noted that the sum of proportions in every vector should be 1 . 
Table 3. Start Vectors for Laramie County Gravel Roads.

\begin{tabular}{|c|c|c|c|c|c|c|}
\hline Distress \& Category & ${ }^{*} \mathbf{F}$ & VP & $\mathbf{P}$ & FA & $\bar{G}$ & VG \\
\hline Initial Vector & 0 & 0 & 0 & 0 & 0 & 1 \\
\hline Potholes & 0.0154 & 0.0061 & 0.0298 & 0.2257 & 0.7064 & 0.0167 \\
\hline Rutting & 0.0152 & 0.0110 & 0.0258 & 0.1669 & 0.7746 & 0.0065 \\
\hline Washboards & 0.0010 & 0.0017 & 0.0352 & 0.3093 & 0.6397 & 0.0131 \\
\hline Loose Aggregate & 0.0045 & 0.0045 & 0.0160 & 0.2146 & 0.7586 & 0.0017 \\
\hline Distress \& Category & $\mathrm{H}$ & M & $\mathrm{L}$ & $\mathrm{N}$ & & \\
\hline Initial Vector & 0 & 0 & 0 & 1 & & \\
\hline Distress \& Category & $\mathrm{P}$ & FA & $\mathrm{G}$ & & & \\
\hline Initial Vector & 0 & 0 & 1 & & & \\
\hline Cross Section & 0.0696 & 0.1189 & 0.8115 & & & \\
\hline Drainage & 0.0750 & 0.1040 & 0.8210 & & & \\
\hline
\end{tabular}

*F: Failed; VP: Very Poor; P: Poor; FA: Fair; G: Good; VG: Very Good; H: High; M: Medium; L: Low.

\subsection{Transition Probability Matrices (TPM)}

In this study, a stationary TPM is developed for each distress type. The developed TPMs will be used to predict the development of each distress with time. In Laramie County and for the purposes of this pilot study, gravel road conditions are available for only one duty cycle. Therefore, average deterioration rates, in points per day, are used to estimate gravel road conditions for the next duty cycle and in the development of the TPM.

The average deterioration rates were used along with the collected data to establish a historical database. In this process, the average deterioration rates were deducted daily from the collected data for a period enough to reach failure for every gravel road. This process provided this study with the necessary historical data to build the Markov-chains. After examining the established historical database, different duty cycles were defined to simplify the Markov-chains building process. Later, the established historical database and the defined duty cycles were used to build the TPM. Hence, both the states and the transition probabilities will have the same cycle length for every deterioration mode. The utilized deterioration rates and the different selected duty cycles are shown in Table 4. It can be noticed that potholes and washboards have the highest deterioration rates compared to the other distresses. The average deterioration rates were estimated, using the same rating scale used in this study, after monitoring 20 well-constructed gravel roads segments at sites in northcentral Wyoming for 10 months [2]. During this period of 10 months, gravel roads were rated weekly. Some distresses required more than a week or even a month to deteriorate from one stage to another. Therefore, the number of days required for each distress condition (i.e. potholes) to deteriorate from one stage to the next was used to calculate the average deterioration rates by points per day. Then, the overall average among all the stages was used to estimate the final deterioration rates used in this study. Considering the dynamic and the arbitrary nature of gravel roads, following this approach saved time, effort, and resources that are required to collect multiple duty cycles historical data.

According to the National Oceanic and Atmospheric Administration (NOAA), the Wyoming northcentral areas are part of the Wyoming climatic division 5, or, what is known as "the Powder, Little Mo and Tongue Drainages" while the data collected in this study was collected from Laramie County which follows the Wyoming climatic division 8 or what is known as "Lower Platte." Both climatic regions share similar short, warm, and dry summers with average precipitation rates between (1.8 to 2.2 ) inches. During the warm season, region 5 has an average daily high temperature around $78^{\circ} \mathrm{F}$ while in region 8 is around $70^{\circ} \mathrm{F}$. During the cold season, region 5 has an average daily high temperature around $45^{\circ} \mathrm{F}$ while in region 8 is around $41^{\circ} \mathrm{F}[23,24]$. Additionally, both regions serve rural similar traffic conditions. Hence, these estimates can be used in this study to develop TPM. Different duty cycles were selected to allow reasonable transitions from one stage to another which can simplify the modeling process.

Table 4. Average Deterioration Rates for Gravel Roads in Wyoming.

\begin{tabular}{lll}
\hline Distress & $\begin{array}{l}\text { Deterioration Rate } \\
\text { (points per day) }\end{array}$ & Duty Cycle (months) \\
\hline Potholes & 0.0397 & 1 \\
Rutting & 0.0216 & 2 \\
Washboards & 0.0429 & 1 \\
Loose Aggregate & 0.01 & 4 \\
Dust & 0.002 & 17 \\
Cross Section (Crown) & 0.002 & 17 \\
Drainage & 0.002 & 17 \\
\hline
\end{tabular}

Table 5 shows a TPM for potholes where rows denote the current state and the columns represent the future state after the transition period. According to this TPM, the probability of a gravel road in a very good (VG), or in a very poor state (VP), to remain in that state is zero. There is a rather high probability (greater than 0.7 ) for a road in a fair $(\mathrm{F})$ or poor state $(\mathrm{P})$ to remain in that state. These results can be attributed to the dynamic nature of these kinds of roads. Frequent light M\&R interventions, such as light blading, are required to keep a gravel road in the very good (VG) state for more than one duty cycle. The same behavior can be noticed for rutting and washboards. When it comes to loose aggregates, dust, drainage, and crown conditions, the deterioration patterns are slower. Thus, a gravel road may stay in the same state for more than one duty cycle as seen in Table 6. For dust, drainage, and cross section the 
deterioration rates are very small. Thus, a cycle of 17 months is assumed to develop the TPM.

Table 5. TPM for Potholes.

\begin{tabular}{lllllll}
\hline & VG & G & FA & P & VP & F \\
\hline VG & 0.000 & 1.000 & 0.000 & 0.000 & 0.000 & 0.000 \\
G & 0.000 & 0.634 & 0.366 & 0.000 & 0.000 & 0.000 \\
FA & 0.000 & 0.000 & 0.701 & 0.299 & 0.000 & 0.000 \\
P & 0.000 & 0.000 & 0.000 & 0.767 & 0.233 & 0.000 \\
VP & 0.000 & 0.000 & 0.000 & 0.000 & 0.000 & 1.000 \\
F & 0.000 & 0.000 & 0.000 & 0.000 & 0.000 & 1.000 \\
\hline
\end{tabular}

Table 6. TPM for Loose Aggregate.

\begin{tabular}{lllllll}
\hline & VG & G & FA & P & VP & F \\
\hline VG & 0.000 & 1.000 & 0.000 & 0.000 & 0.000 & 0.000 \\
G & 0.000 & 0.448 & 0.552 & 0.000 & 0.000 & 0.000 \\
FA & 0.000 & 0.000 & 0.918 & 0.082 & 0.000 & 0.000 \\
P & 0.000 & 0.000 & 0.000 & 0.491 & 0.509 & 0.000 \\
VP & 0.000 & 0.000 & 0.000 & 0.000 & 0.000 & 1.000 \\
F & 0.000 & 0.000 & 0.000 & 0.000 & 0.000 & 1.000 \\
\hline
\end{tabular}

\subsection{Models Development}

Finally, the TPM and the initial vector are used together to build Markov chains for the different deterioration modes. For example, Table 7 shows a Markov chain for loose aggregate and the associated weighted average condition for each stage. The weighted averages were calculated based on the actual possible ratings that a rater might give to a road in the field and the possible transition probabilities. For example, the average weighted loose aggregate condition of a gravel road can be estimated as follows:

1. After 4 months $=0 * 9+1 * 7.5+0 * 5.5+0 * 3.5+0 * 2+$ $0 * 1=7.500$.

2. After 12 months $=0 * 9+0.201 * 7.5+0.754 * 5.5+$ $0.045 * 3.5+0 * 2+0 * 1=5.811$.

These weighted averages, accompanied with the time duration, are used to predict the performance model for loose aggregate as shown in Figure 2. The value $\mathrm{y}$ in Figure 2 denotes the predicted rating at a given age (Months).

Table 7. Markov Chain for Loose Aggregate.

\begin{tabular}{|c|c|c|c|c|c|c|c|c|}
\hline Stage & Month & VG & $\mathbf{G}$ & FA & $\mathbf{P}$ & $\mathbf{V P}$ & $\mathbf{F}$ & Average Condition \\
\hline 0 & 0 & 1.000 & 0.000 & 0.000 & 0.000 & 0.000 & 0.000 & 9.000 \\
\hline 1 & 4 & 0.000 & 1.000 & 0.000 & 0.000 & 0.000 & 0.000 & 7.500 \\
\hline 2 & 8 & 0.000 & 0.448 & 0.552 & 0.000 & 0.000 & 0.000 & 6.396 \\
\hline 3 & 12 & 0.000 & 0.201 & 0.754 & 0.045 & 0.000 & 0.000 & 5.811 \\
\hline 4 & 16 & 0.000 & 0.090 & 0.803 & 0.084 & 0.023 & 0.000 & 5.431 \\
\hline 5 & 20 & 0.000 & 0.040 & 0.787 & 0.107 & 0.043 & 0.023 & 5.113 \\
\hline 6 & 24 & 0.000 & 0.018 & 0.744 & 0.117 & 0.055 & 0.066 & 4.815 \\
\hline 7 & 28 & 0.000 & 0.008 & 0.693 & 0.119 & 0.060 & 0.120 & 4.529 \\
\hline 8 & 32 & 0.000 & 0.004 & 0.641 & 0.115 & 0.060 & 0.180 & 4.256 \\
\hline 9 & 36 & 0.000 & 0.002 & 0.590 & 0.109 & 0.059 & 0.240 & 3.999 \\
\hline 10 & 40 & 0.000 & 0.001 & 0.543 & 0.102 & 0.056 & 0.299 & 3.758 \\
\hline 11 & 44 & 0.000 & 0.000 & 0.499 & 0.095 & 0.052 & 0.354 & 3.535 \\
\hline 12 & 48 & 0.000 & 0.000 & 0.458 & 0.087 & 0.048 & 0.406 & 3.329 \\
\hline 13 & 52 & 0.000 & 0.000 & 0.421 & 0.080 & 0.044 & 0.454 & 3.139 \\
\hline 14 & 56 & 0.000 & 0.000 & 0.386 & 0.074 & 0.041 & 0.499 & 2.964 \\
\hline 15 & 60 & 0.000 & 0.000 & 0.355 & 0.068 & 0.038 & 0.540 & 2.803 \\
\hline 16 & 64 & 0.000 & 0.000 & 0.325 & 0.062 & 0.035 & 0.577 & 2.655 \\
\hline 17 & 68 & 0.000 & 0.000 & 0.299 & 0.057 & 0.032 & 0.612 & 2.520 \\
\hline 18 & 72 & 0.000 & 0.000 & 0.274 & 0.053 & 0.029 & 0.644 & 2.395 \\
\hline 19 & 76 & 0.000 & 0.000 & 0.252 & 0.048 & 0.027 & 0.673 & 2.281 \\
\hline 20 & 80 & 0.000 & 0.000 & 0.231 & 0.044 & 0.025 & 0.700 & 2.176 \\
\hline 21 & 84 & 0.000 & 0.000 & 0.212 & 0.041 & 0.023 & 0.724 & 2.079 \\
\hline 22 & 88 & 0.000 & 0.000 & 0.195 & 0.037 & 0.021 & 0.747 & 1.991 \\
\hline 23 & 92 & 0.000 & 0.000 & 0.179 & 0.034 & 0.019 & 0.768 & 1.910 \\
\hline 24 & 96 & 0.000 & 0.000 & 0.164 & 0.032 & 0.017 & 0.787 & 1.835 \\
\hline
\end{tabular}

Loose Aggregate

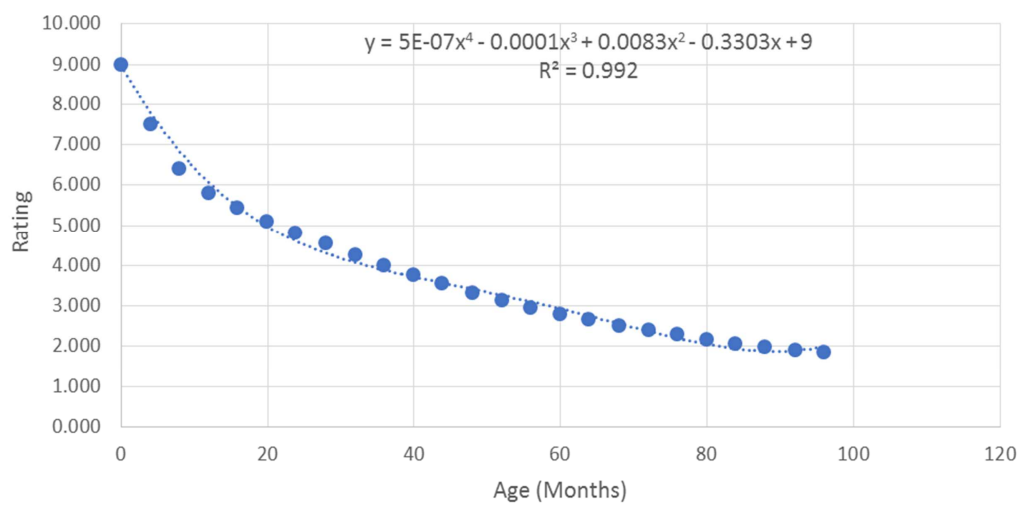

Figure 2. Loose Aggregate Performance Model. 
Figure 3 shows another representation of the developed Markov chain using a bar chart based on the start vector of loose aggregate. This chart shows the probability of any gravel road segment to be in a specific condition state at any given period of time. For example, a gravel road has a $55 \%$ chance to be in fair loose aggregate condition after 8 months of construction. The same segment has a $45 \%$ chance to be in good loose aggregate conditions at the same age. Based on the current conditions of the network (i.e. start vector), the probability of having a gravel road at the first month of it is service life in the very good category is less than $1 \%$.

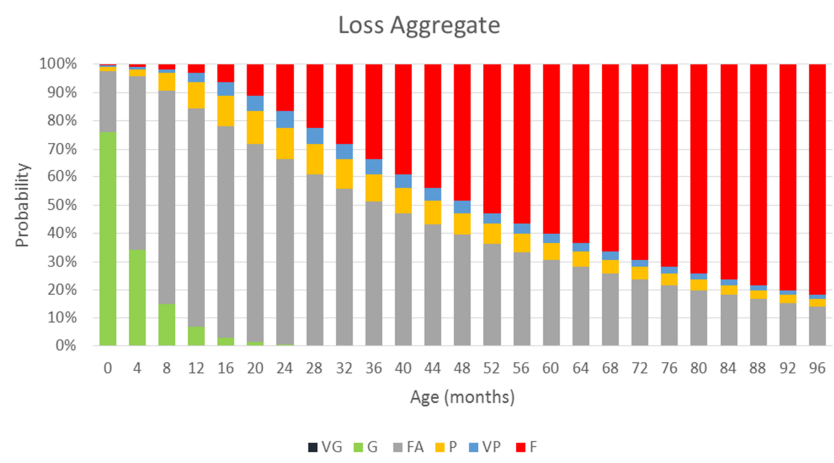

Figure 3. Markov Chain for Loose Aggregate.

Table 8 shows a summary of the developed performance prediction models using the MC approach for all the distresses according to the GRRS. According to this table, and based on the actual conditions and deterioration rates, crown and drainage have similar predicted performance equations. This can be attributed to the strong link between drainage and crown conditions. Roads with poor drainage tend to allow more water to filtrate the subgrade, which increases the likelihood of a cross section failure. The developed prediction equations are based on the GRRS system which is a modification to the PASER system. This system is the most popular system to evaluate gravel roads in the US [12]. Thus far, and at least in the US, these prediction equations are unique and thoroughly describe the deterioration modes of gravel roads based on a popular visual evaluation method.

Table 8. Performance Models for Gravel Roads.

\begin{tabular}{ll}
\hline Distress Index & Model \\
\hline Potholes & $\mathrm{Y}=-0.0008 \mathrm{X}^{3}+0.0504 \mathrm{X}^{2}-1.0632 \mathrm{X}+9$ \\
Rutting & $\mathrm{Y}=0.000005 \mathrm{X}^{4}-0.0006 \mathrm{X}^{3}+0.027 \mathrm{X}^{2}-0.645 \mathrm{X}+9$ \\
Washboards & $\mathrm{Y}=-0.0009 \mathrm{X}^{3}+0.0524 \mathrm{X}^{2}-1.0641 \mathrm{X}+9$ \\
Loose Aggregate & $\mathrm{Y}=0.0000005 \mathrm{X}^{4}-0.0001 \mathrm{X}^{3}+0.0083 \mathrm{X}^{2}-0.33 \mathrm{X}+9$ \\
Dust & $\mathrm{Y}=0.00002 \mathrm{X}^{3}-0.0012 \mathrm{X}^{2}-0.0398 \mathrm{X}+4$ \\
Crown & $\mathrm{Y}=0.00003 \mathrm{X}^{3}-0.0017 \mathrm{X}^{2}-0.0392 \mathrm{X}+3$ \\
Drainage & $\mathrm{Y}=0.00003 \mathrm{X}^{3}-0.0017 \mathrm{X}^{2}-0.0392 \mathrm{X}+3$ \\
\hline
\end{tabular}

Y: Condition index (points); X: Time in months.

Figure 4 graphically shows all the developed predicted performance models. As seen from this figure, the fastest distresses to reach failure conditions are washboards and potholes. These two distresses can reach failure $(\mathrm{R}<2)$ within only 13 months, and both distresses have similar performance throughout the road service life. For rutting, it takes about 28 months to reach failure conditions. The deterioration that is based on loose aggregate condition is the longest. A gravel road requires about 88 months to reach failure $(\mathrm{R}<2)$ compared to cross section, dust, and drainage based deteriorations (34 months). Nonetheless, gravel road conditions are sometimes harder to predict.

Gravel road deterioration modes are interrelated to each other and every distress may encourage the development of other distresses which is apparent from the Pearson correlation matrix shown in Table 9. According to this matrix, there are strong positive correlations among potholes, washboards, and rutting. The same association can be noticed among roadside drainage, crown, and rutting. Also, there is an association among dust, loose aggregate, and washboards, but the association is not as strong. Lastly, it can be noticed that potholes, washboards, and rutting are most highly correlated to the overall ride quality. Thus, these deterioration modes are the main contributing factors to the comfort of road users and the reason behind the failure of gravel roads.
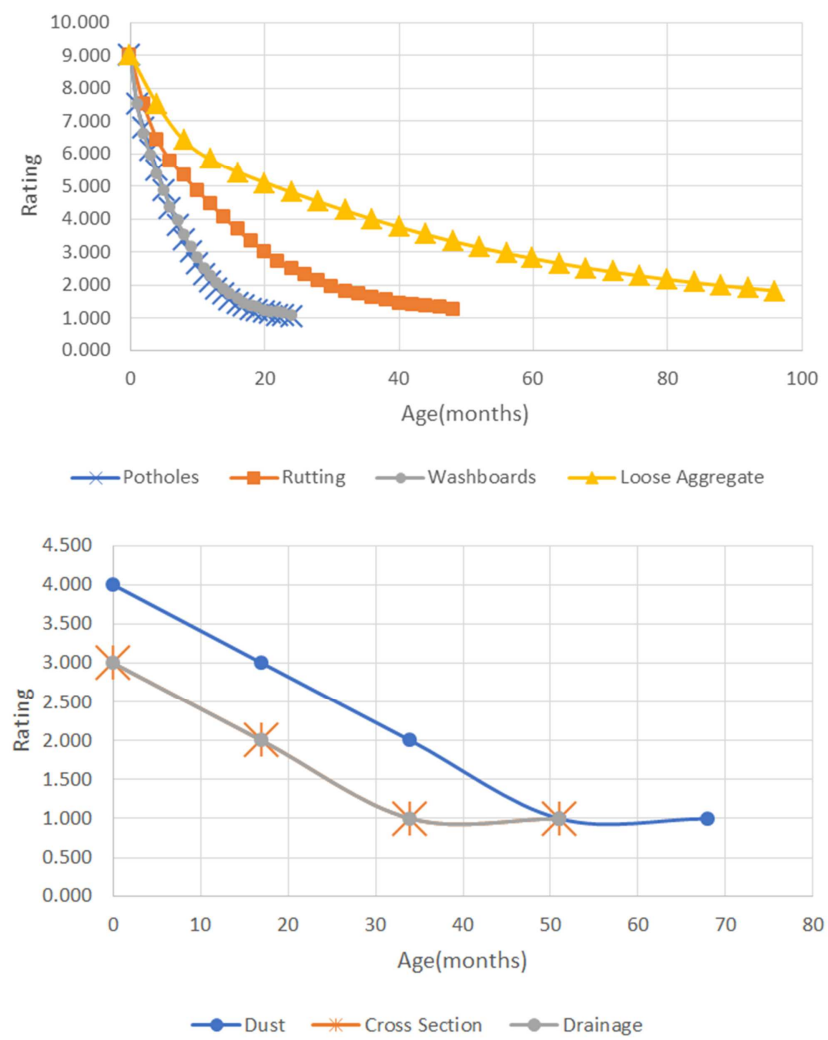

Figure 4. Markov Performance Models of Average Condition Values for All Distresses. 
Table 9. Pearson Correlation Matrix.

\begin{tabular}{|c|c|c|c|c|c|c|c|c|}
\hline & Overall & Potholes & Rutting & Washboards & Loose Aggregate & Dust & Crown & Drainage \\
\hline Overall & 1.000 & 0.775 & 0.655 & 0.566 & 0.210 & -0.065 & 0.371 & 0.331 \\
\hline Potholes & 0.775 & 1.000 & 0.592 & 0.529 & 0.144 & -0.029 & 0.271 & 0.260 \\
\hline Rutting & 0.655 & 0.592 & 1.000 & 0.345 & 0.265 & 0.080 & 0.459 & 0.419 \\
\hline Washboards & 0.566 & 0.529 & 0.345 & 1.000 & 0.164 & 0.247 & 0.074 & 0.081 \\
\hline Loose Aggregate & 0.210 & 0.144 & 0.265 & 0.164 & 1.000 & 0.208 & 0.097 & 0.042 \\
\hline Dust & -0.065 & -0.029 & 0.080 & 0.247 & 0.208 & 1.000 & -0.094 & -0.120 \\
\hline Drainage & 0.331 & 0.260 & 0.419 & 0.081 & 0.042 & -0.120 & 0.790 & 1.000 \\
\hline
\end{tabular}

\section{Summary and Conclusions}

The WY2/ LTAP is currently in the process of developing a GRMS in Wyoming. As part of this GRMS, a comprehensive optimization model will be established to support the decision making process related to the $M \& R$ projects. Estimating the potential service life of any road within the network is an essential part of this optimization process. Thus, this study fits multiple performance models that are specific to the gravel roads in Wyoming. The developed prediction equations included all the possible distresses that may occur at a gravel road surface according to the GRRS manual. Laramie County was selected to perform a pilot study prior to any statewide implementation of the new GRMS. A team of 2 raters drove the entirety of the gravel roads in the network for Laramie County and rated these roads according to the GRRS and RQRG manuals. This exhaustive data collection effort resulted in a comprehensive dataset that was used to develop the performance models. Markov chains, were used to develop the performance prediction equations from a probabilistic modeling perspective. Historical or time series condition data was not available for Laramie gravel roads. Therefore, average deterioration rates obtained from previous studies conducted in Wyoming, in points per day, were used to predict the next duty cycle conditions and to develop stationary TPMs. Later on, initial vectors using the current condition data, together with the TPM, were used to develop the Markov chains. For each distress, the average weighted condition and the time duration for every stage were used to develop the final performance prediction models. Generally, it was found that the average service life of a gravel road is around 12 months without any maintenance intervention. Also, potholes, rutting, and washboards are the main failure modes for these kinds of roads. Moreover, various gravel roads deterioration modes are simultaneously interrelated and interact with each other. The developed Models were used to predict the deterioration patterns and the remaining service life during the optimization process of gravel roads for the purposes of setting M\&R strategies. The GRRS system, followed in this study, is a modification to the PASER system which is the most popular system to evaluate gravel roads in the US [12]. Therefore, the developed performance prediction equations, and the implemented methodology, could be used in other GRMS in the US.

\section{Recommendation}

The established performance prediction equations should be used in developing a comprehensive optimization model for gravel roads in Wyoming. Other local agencies in the US can follow the same methodology developed in this study to develop their own prediction equations for evaluation of the condition of road conditions. Additionally, the developed prediction equations are based on modifications to the PASER system which means that the new equations might be transferable for direct use by other local agencies in the US.

\section{Acknowledgements}

The authors would like to thank Mountain Plains Consortium (MPC), Wyoming Counties, and (WYDOT) for supporting this research study. We would also like to thank Omar Albatayneh for his assistance in this research.

\section{References}

[1] Mannisto, V., and Tapio, R. A. I. M. O., 1990. Maintenance management on gravel roads. Transportation Research Record: Journal of the Transportation Research Board, No. 1268, 170-172.

[2] Huntington, G., and K. Ksaibati. 2007. Gravel Roads Surface Performance Modeling. Transportation Research Record: Journal of the Transportation Research Board, No. 2016, pp. 56-64. https://doi.org/10.3141/2016-07.

[3] Chamorro, A., and Tighe, S. 2011. Condition performance models for network-level management of unpaved roads. Transportation Research Record: Journal of the Transportation Research Board, (2204), 21-28.

[4] World Bank. 2018. Roads and Highways [Online]. Available from: http:/web.worldbank.org/WBSITE/EXTERNAL/TOPICS/EXTT RANSPORT/EXTROADSHIGHWAYS/0, menuPK: 338667 pagePK: 149018 piPK: 149093 theSitePK: 338661, 00.html. [Accessed 15 January 2018].

[5] Giummarra, G. 2000. Unsealed roads manual: guidelines to good practice (No. USR001). 3rd ed. ARRB Group, Ltd., Vermont South, Victoria, Australia, 2009.

[6] Burger, A., Henderson, M., and Van Rooyen, G., 2007. Development of scheduling algorithms for routine maintenance of unsealed roads in Western Cape Province, South Africa. Transportation Research Record: Journal of the Transportation Research Board, NO. 1989, 240-249. 
[7] van Zyl, G., Henderson, M., and Uys, R., 2007. Applicability of existing gravel-road deterioration models questioned. Transportation Research Record: Journal of the Transportation Research Board, No. 1989, 217-225.

[8] Chamorro, A., \& Tighe, S., 2009. Development of a management framework for rural roads in developing countries: integrating socioeconomic impacts. Transportation Research Record: Journal of the Transportation Research Board, No. 2 093, 99-107.

[9] Huntington, G., and Ksaibati K., 2011a. Implementation guide for the management of unsealed gravel roads. Transportation Research Record: Journal of the Transportation Research Board, No. 2205, 189-197.

[10] Chamorro, A., and Tighe, S. L. 2015. Optimized maintenance standards for unpaved road networks based on costeffectiveness analysis. Transportation Research Record: Journal of the Transportation Research Board, No. 2473, 5665 .

[11] Walker, D. 1989. Gravel PASER Manual: Pavement Surface Evaluation and Rating. Wisconsin Transportation Information Center, Madison.

[12] Huntington, G., and Ksaibati, K., 2015. Visual assessment system for rating unsealed roads. Transportation Research Record: Journal of the Transportation Research Board, No. 2474, 116-122.

[13] Hassan, R., Lin, O., and Thananjeyan, A., 2015. Markov Chain modelling of pavement surfacing. Transportation Research Record 2473, pp. 3-12. https://doi.org/10.3141/2473-01.

[14] Costello, S. B., et al., 2005. Stochastic model for strategic assessment of road maintenance. Proceedings of the Institution of Civil Engineers, Transport, 158 (TR4), 203-211.

[15] De Melo e Silva, F., et al., 2000. Proposed pavement performance models for local government agencies in Michigan. Transportation Research Record 1699, Paper No. 00-0986.
[16] Uchwat, C. and MacLeod, D., 2012. Case studies of regression and Markov chain models. Proceedings of pavement performance case studies session of the 2012 conference of the transportation association of Canada Fredericton. New Brunswick.

[17] Abaza, K. A. 2016. Simplified staged-homogenous Markov model for flexible pavement performance prediction. Road Materials and Pavement Design, 17 (2), 365-381.

[18] Hassan, R., Lin, O., and Thananjeyan, A., 2017. Probabilistic modelling of flexible pavement distresses for network management. International Journal of Pavement Engineering, 18 (3), 216-227.

[19] Osorio-Lird, A., Chamorro, A., Videla, C., Tighe, S., and Torres-Machi, C. 2017. Application of Markov chains and Monte Carlo simulations for developing pavement performance models for urban network management. Structure and Infrastructure Engineering, 1-13.

[20] Huntington, G., and Ksaibati, K., 2009. Annualized Road Works Cost Estimates for Unpaved Roads. Journal of Transportation Engineering 135 (10), 702-710.

[21] Archondo-Callao, R., 2001. Roads Economic Decision Model (RED) for Economic Evaluation of Low-Volume Roads. Africa Regional Office, World Bank, Washington, D. C.

[22] Bushman, W., Freeman, T., and Hoppe, E., 2005. Stabilization techniques for unpaved roads. Transportation Research Record: Journal of the Transportation Research Board, (1936), 28-33.

[23] National Oceanic and Atmospheric Administration (NOAA). 2018. [Online]. Available from: http://www.cpc.ncep.noaa.gov/products/analysis_monitoring/r egional monitoring/CLIM_DIVS/states_counties_climatedivisions.shtml. [Accessed 25 October 2018].

[24] U.S. Climate Data. 2018. [Online]. Available from: https://www.usclimatedata.com/climate/laramie/wyoming/unit ed-states/uswy0102. [Accessed 25 October 2018]. 